\title{
Evaluation of Waste Cooking Oil as Sustainable Binder for Building Blocks
}

\author{
Johnson Olufemi Adebayo ${ }^{1 *}$,Madzlan Napiah ${ }^{2}$, Kamaruddin Ibrahim $^{1}$ and Mohamad \\ Raduan. Kabit ${ }^{3}$ \\ ${ }^{1}$ Department of Civil Engineering, School of Energy, Geoscience, Infrastructure and Society, Heriot- \\ Watt University Malaysia, 62200 Putrajaya, Malaysia \\ ${ }^{2}$ Department of Civil and Environmental Engineering, Universiti Teknologi PETRONAS, 31750 Seri \\ Iskandar, Tronoh, Malaysia \\ ${ }^{3}$ Department of Civil Engineering Faculty of Engineering Universiti Malaysia Sarawak, 94300 Kota \\ Samarahan, Sarawak, Malaysia
}

\begin{abstract}
Increasing depletion of material resources and concern for the environment has led to the great quest for degradable and environmentally sustainable material in various industries in recent years. Application of Waste Vegetable oils as a renewable and biodegradable binder material was explored in this work. Block samples were prepared with $10 \%$ liquid binder of vegetable oil, compacted with 75 impact blows and thermally cured in a conventional oven at temperature ranges of $160-200^{\circ} \mathrm{C}$. This study explores the effectiveness of waste cooking oil as a novel binder in the production of building block, called WasteVege block. Important parameters such as optimum binder content, optimum curing temperature, and optimum curing age were established. The mechanical and physical properties of the product were examined, the result shows that compressive strength in ranges of $5-34 \mathrm{MPa}$ was achieved, initial rate of absorption (IRA), water absorption, efflorescence, and wet/dry durability of the product exhibit acceptable values within the threshold of required standards.
\end{abstract}

\section{Introduction}

Concern for the environment, increasing waste generation, and reduction in non-renewable resources has given birth to increasing demand in the application of renewable resources. Cooking oils are a renewable resource that can be used as reliable starting material to access new products to a wide array of structural and functional variations. Its availability and lower cost make it an industrially attractive raw material for various industries. Its annual global production has increased from 84.6 million tons (Mt) in 1999/ 2000 to 137.3 Mt in 2009/2010 with an increase of $62 \%$ [1].

Increased demand for the application of natural products in solving environment, waste disposal, and reduction in non-renewable resources problem has risen in the recent time.

\footnotetext{
* Corresponding author: $\underline{\text { O.Johnson@hw.ac.uk }}$
} 
This increasing interest is due to the development in the support of producing renewablebased materials that offer sustainability, reduced energy consumption, low cost and comparable performance to composites from non-bio renewable resources [2].

The typical practice in many homes and commercial Centre is to discard frying fat or oil after a prolonged use, because of its excessive foaming, excessive smoke and undesirable flavor. Thus, the terms waste vegetable oil refers to cooking oil, which has been used in food production and which is no longer viable for its intended use. Up to $30 \%$ of used fats and oils are discarded every week in commercial frying operations, creating a sizeable problem in terms of disposal [3].

In the UK alone caterers produce at least 120,000 tons of waste cooking oil each year whilst in the US, restaurants produce a staggering 1.135 million tons annually $[4,5]$. Used cooking oil from households has the potential to significantly add to this figure, but has been excluded from further calculations because it is not currently collected [6]. Disposal of Waste edible oils and fats is a major concern in many parts of the world. [7].

This study investigates the fundamental understanding of the very complex physicalchemical Oxy-polymerization reactions (mechanisms \& reaction rates) resulting in the binding process that occurs within the thin films of heat cured oil coating the aggregate particles. Quantitative materials properties, including hardness and modulus, were determined and correlated to the severity of oil oxidation. Such information does not exist and will thus enable appropriate optimization of the system ingredients and curing conditions, thus making the resulting end product a commercially viable alternative to conventional blocks.

\section{Materials and methods}

\subsection{Aggregates}

The Sand used were characterized to determine the particle size distribution, specific gravity, and the chemical composition. The sieve size distribution was done in accordance with ASTM C 136 96a [8], the specific gravity was determined in accordance with ASTM C127-88 \& C128- 88 [9].

The chemical compositions of the sand samples were examined using X-Ray Fluorescence (XRF) spectroscopy. XRF is fundamental equipment used for the quantitative and qualitative elemental analysis of materials. It is suitable for measurement of various materials for the determination of elemental concentration, determination of specific and trace elements in intricate specimen matrices.

\subsection{Waste Cooking oil}

The Waste Vegetable oil used was collected from Universiti Teknologi Petronas student Hostel cafeteria. The solid particles were removed through filtration before use. The fatty acid content was determined.

\subsection{Specimen Preparation}

For each sample a $600 \mathrm{~g}$ mixture of two types of sands (river and crushed) was used at ratio $1: 1$. Equal quantities of the sands were weighed and mixed together. The binder was then measured; the binder content was $10 \%$ of all samples by weight and was then added to the 
sand. After thorough mixing, the freshly prepare mixes were placed in cylindrical moulds $(50 \mathrm{~mm} \times 100 \mathrm{~mm})$ and compacted using a Marshall compacting machine with 75 impact blows on one face. The compacted specimens were extruded from their moulds and then thermally cured in a conventional oven at $170^{\circ} \mathrm{C}$ for 10 and half days.

\section{Testing procedure}

Physical and chemical properties of the Wastevege block were evaluated, the test specimens were prepared in triplicate, cured, and cored in accordance with adopted standards. The testing procedures employed are as follows; compressive strength, initial rate of absorption, water absorption, efflorescence, wet/dry durability and creep

\subsubsection{Compressive strength of wastevege block}

Compression test was done in accordance with ASTM C39/C 39MM [10]. This test method covers determination of compressive strength of cylindrical concrete specimen such as molded cylinder and drilled cores. The load was applied continuously without shock. The load was applied at the rate of movement corresponding to a stress rate on the specimen of $0.25+/-0.05 \mathrm{MPa} / \mathrm{s}$.

\subsubsection{Water absorption test}

The water absorption test was performed in accordance with ASTM C67-03a [11] to determine the percentage amount of water that a brick/block can absorb. 24 hours cold water absorption test and 5 hours boiling tests were conducted on cured samples the values of the cold-water absorption, boiling water absorption and saturation coefficient of all specimens were determined.

\subsubsection{Initial rate of absorption test}

The initial rate of absorption (IRA) test was done in accordance with ASTM C67- 03a [11] to measure the amount of water absorbed in one minute through the bed face of the block. IRA helps to determine the design of the mortal for block bonding since it measures the block suction.

In a masonry unit the ability of the block to absorb water and the capability of the bonding mortal to retain the needed water for proper hydration of cement determines how strong and good the bond strength. High rate and low rate of absorption can considerably affect the bond. The optimum value of the IRA is considered to be between 0.5 and 1.5 $\mathrm{kg} / \mathrm{m} 2 / \mathrm{min}$.

\subsubsection{Efflorescence}

Standard test method ASTM C67-03a [11] was used to determine the presence of soluble salts that come to the surface when the block dries. The source of these soluble salts depends on the raw materials used in the production process. 


\subsubsection{Wet and dry durability test}

This test evaluates the resistance of the stabilized block to the natural weathering stresses of repeated wetting and drying cycles. The test was carried out in accordance with ASTM4843 [12]. Six (6) cured samples of WasteVege block were subjected to ten test cycles. Each cycle consists of a period of five hours submerged under water and 42 hours in an oven under low drying conditions $\left(71^{\circ} \mathrm{C}\right)$. The weight loss after each cycle was measured. After the ten cycles, the total sample weight loss was determined.

\subsubsection{Creep test}

Creep test was carried out on the samples in accordance with ASTM C512-02 [13]. 10 cylindrical samples of $100 \mathrm{~mm}$ diameter by $38 \mathrm{~mm}$ thickness were used for the test. All the samples had their end surface, grounded to within 0.5 degrees of parallel. The test was carried out on the sample using load frames and the samples were loaded using a static deadweight. There was no attempt to hinder moisture gain or loss from the samples before or during the test period.

The strain was monitored using a $50 \mathrm{~mm}$ Demec gauge attached to each sample before being stacked into a load frame. Measurement of the points was taken before loading, immediately after loading, and on a daily basis for 3 weeks

\subsubsection{Fourier Transform Infrared (FTIR)}

Spectrum One/BX Manufactured by Perkin Elmer Inc., by FR-DTGS detector, wave range of $7800-350 \mathrm{~cm}^{-1}$ and resolution of $0.5 \mathrm{~cm}^{-1}$ to $64 \mathrm{~cm}^{-1}$ attached with high-vacuum purge system (HVPS) with residual gauge analyser was used to determine the chemical composition of the oil cured at different ages.

\section{Results and discussion}

The characterization of the materials used (aggregates and binder) is as follows:

\subsubsection{Grain size distribution}

The ASTM C136 procedure was used to determine the sieve analysis of coarse and fine aggregate [8]. The particle size distribution curve of the two type sands was plotted from the coarsest particle size down to the finest particle size. As shown in Fig. 1 the curve indicates that the sands are well graded and suitable for the production of building blocks. 


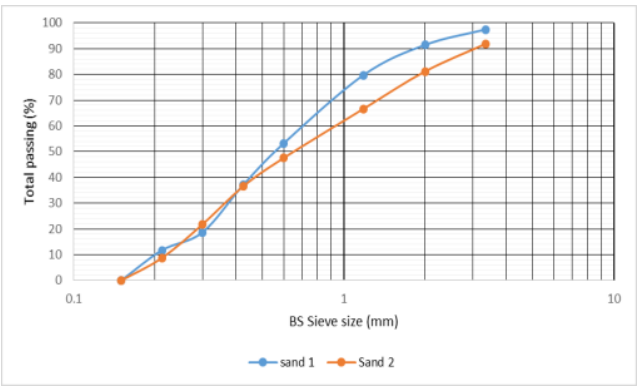

Fig. 1. Particle size distribution of sand

\subsubsection{Specific gravity initial}

The aggregate specific gravity wad determined according to ASTM C 127 and ASTM C128 respectively [9]. The values for sand type I are 2.6519 and 2.5707 for helium pycnometer and ASTM C 127 respectively, while for sand type II are 2.6759 and 2.6474 for helium pycnometer and ASTM C 127 respectively.

\subsubsection{X-Ray Fluorescent (XRF) elemental composition}

Aggregate composition has a significant effect on the properties performance of the end product. Aggregates compositions vary based on the sources. The elements in the sand samples were exposed to a source of high intensity X-rays, fluorescent X-rays were emitted from the samples at energy levels unique to those elements. The source illuminates the sample and emitted radiation from the samples was measured by a detector.

The river sand has the highest percentage of Silica $\mathrm{SiO}_{2}(85.28 \%)$, followed by crushed sand (79.8\%). Principal compounds in river sand are $\mathrm{SiO}_{2}, \mathrm{Al}_{2} \mathrm{O}_{3}$, and $\mathrm{CaO}$, whilst crushed sand contained $\mathrm{SiO}_{2}, \mathrm{~K}_{2} \mathrm{O}$, and $\mathrm{Al}_{2} \mathrm{O}_{3}$.

\subsubsection{Waste cooking oil composition}

The characterization of the waste vegetable oil was carried out to assess the effect of it composition on it binder ability performance, the fatty acid content was investigated using gas chromatography mass spectrometer (GC/MS) with conditions; oven temperature was operated by starting at $80^{\circ} \mathrm{C}$, holding it for 2 minutes, the temperature was increased at a rate of $20^{\circ} \mathrm{C}$ per minute until $125^{\circ} \mathrm{C}$ and was held for 1 minute before it was increased again at a rate of $3{ }^{\circ} \mathrm{C}$ per minute until $220^{\circ} \mathrm{C}$. At $220^{\circ} \mathrm{C}$ it was held for 5 minute to ensure that all high carbonyl number fatty acid was eluted. Standard methods for the analysis of oils, fats, and derivatives [14] were adopted. Analysis of the specimen was done by syringe, $0.2 \mu \mathrm{l}$ of fatty acid standard solution was injected in accordance with the standard, and then $0.2 \mu \mathrm{l}$ of the test sample solution was injected. The composition is shown in Table 1 . 
Table 1. Fatty acid composition of waste cooking oil

\begin{tabular}{|c|c|}
\hline Type of fatty acid & Wt. $\%$ \\
\hline Myristic saturated C14 & 8.8 \\
\hline Palmitic saturated C16:0 & 28.3 \\
\hline Stearic saturated C18:0 & 12.3 \\
\hline Oleic monounsaturated C18: 1 & 5.1 \\
\hline Linoleic polyunsaturated C18:2 & 45.5 \\
\hline Total & 100 \\
\hline
\end{tabular}

\subsubsection{Mechanical and physical properties}

Specimens were prepared using established optimum binder content (OBC) and optimum curing age (OCA) and curing temperatures at ranges of $160-200^{\circ} \mathrm{C}$ to determine the optimum curing temperature(OCT). The engineering properties evaluated in the course of this study were based on the samples prepared with the OBC, and OCA through which the optimum curing temperature will be determined.

\section{1) Compressive strength, stiffness and strain capacity of WasteVege block:}

Curing age-dependent compressive strength properties of the WasteVege block were investigated using Universal Testing Machine (UTM) of $100 \mathrm{KN}$ capacity. The testing enables us to obtain results relating to compressive strength and stress-strain, which was used to determine the stiffness. This test was carried out in accordance with ASTM C39/C39MM [10]. The axial deformation of the samples was measured accurately by an inbuilt mechanism in the UTM from initiation of loading through failure. The load and the results were automatically recorded by the machine at 50hertz throughout the testing period.

The high compressive strength was observed at 10.5 days of $170^{\circ} \mathrm{C}$ curing temperature samples to be between $32-34 \mathrm{MPa}$, followed by the sample at $160^{\circ} \mathrm{C}, 180^{\circ} \mathrm{C}$, and $190^{\circ} \mathrm{C}$. Sample at $200^{\circ} \mathrm{C}$ exhibit the lowest compressive strength. This shows that the full oxidation reaction and curing that enhance high compressive strength occurs at $170^{\circ} \mathrm{C}$, though the oxidation reaction started at $160^{\circ} \mathrm{C}$ but complete curing was not achieved as further shown by physical observation on the samples. At high temperature the binder lost its binding ability on the aggregates leading to disintegration causing the lower results recorded for compressive strength, this was observed in the samples cured at 190 and $200^{\circ} \mathrm{C}$.

Table 2 shows the results of the average compressive strength, stiffness, energy absorbed and porosity of samples cured at different temperatures, it can be observed that samples cured at $170^{\circ} \mathrm{C}$ exhibits the highest values in term of strength. The energy absorbed by the sample during compression loading was represented by the area under the stress-strain curve, a linear relationship between energy absorbed and compressive strength was observed thus the higher the energy absorbed the greater the compressive strength, this correlates with the fact that higher energy absorbed by a sample can be related to higher compressive strength [15]. 
Table 2. Compressive Strength, Stiffness, Energy absorbed and Porosity

\begin{tabular}{|c|c|c|c|c|c|}
\hline & $\mathbf{1 6 0}^{\circ} \mathbf{C}$ & $\mathbf{1 7 0}^{\circ} \mathbf{C}$ & $\mathbf{1 8 0}^{\circ} \mathbf{C}$ & $\mathbf{1 9 0}^{\circ} \mathbf{C}$ & $\mathbf{2 0 0}^{\circ} \mathbf{C}$ \\
\hline $\begin{array}{c}\text { Compressive } \\
\text { Strength (MPa) }\end{array}$ & 29.04 & 34.28 & 23.00 & 22.94 & 5.74 \\
\hline Stiffness(MPa) & 1969 & 2015.75 & 1108.83 & 549.5 & 263.0 \\
\hline $\begin{array}{c}\text { Energy } \\
\text { Absorbed } \\
\left(\mathrm{J} / \mathrm{m}^{3}\right)\end{array}$ & 1337.2 & 1924.62 & 1108.67 & 955.39 & 945.94 \\
\hline Porosity (\%) & 11.526 & 13.0 & 12.56 & 12.72 & 17.66 \\
\hline
\end{tabular}

\section{2) Water Absorption Test:}

Five cured samples were used to the 24 hours cold water absorption test with all their rough edges or loose particles ground off and are free of cracks. Specimens were dry and cool in accordance with ASTM C67-03a [11], and their weight was taken before they were submerged in clean distilled water at $28^{\circ} \mathrm{C}$ for the specified time, then were removed and the surface dried and weighed.

The specimens that have been subjected to the cold-water were used for the 5-hours boiling test. The average boiling water absorption of $8.9 \%$ and average saturation coefficient of 2.19 was recorded for WasteVege block.

\section{3) Initial rate of Absorption:}

Five specimens were dry and cooled in accordance with ASTM C67- 03a [11] applicable procedures and their initial rate of absorption (IRA) were determined. The average initial rate of absorption of all WasteVege block specimens tested is 0.5 $\mathrm{g} / \mathrm{min} / 193.55 \mathrm{~cm}^{2}$, while the optimum value of the IRA is considered to be between 0.5 and 1.5 .

\section{4) Efflorescence:}

Ten (10) full sizes cured blocks that were organized into five pairs as to establish that specimens of each pair have the same appearance as possible. One set of specimen from each of the five pairs was partially immersed in distilled water to a depth of approximately $25.4 \mathrm{~mm}$ for 7 days in the drying room. While the other set for each of the five pairs were stored in the drying room without any contact with moisture. After 7 days, they set immersed in water was carefully observed and both sets were dried in an oven for 24 hours. At the end of 24 hours in the oven both sets of specimens were carefully examined and compared by observing the top and all sides of each specimen from a distance of $3 \mathrm{~m}$ under an illumination. The examination shows no difference in both sets of specimen. It is therefore concluded that the specimens were not effloresced.

\section{5) Wet/Dry Durability test:}

The resistance of the WasteVege block to natural weathering stresses of repeated wetting and drying cycles was investigated in accordance with ASTM D 4843 Method [12]. Six cured test samples were subjected to ten test cycles for each block type. Each cycle consists of a period of five hours submerged under water and 42 hours in an oven at $71^{\circ} \mathrm{C}$ temperature. The weight loss was determined after each cycle as shown in Fig. 2. After the ten cycles, the total sample weight loss was determined. The results show that the specimen remained intact after the 10 th cycle. 


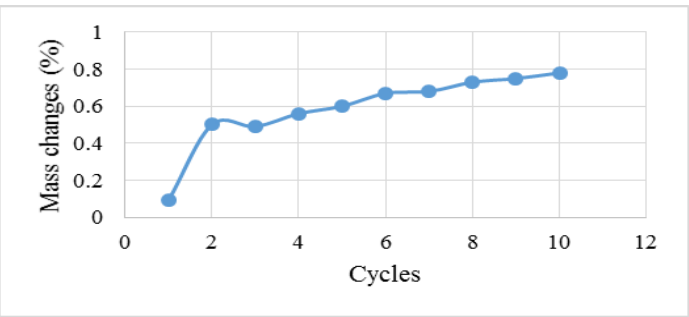

Fig. 2. Mass change of wastevege block during wet/dry test

\section{6) Creep test result}

This test was introduced to investigate the stability of the WasteVege block under static load and to confirm its efficiency as a masonry unit. The test was conducted on cylindrical samples prepared at $170^{\circ} \mathrm{C}$ and cured for 10 and a half days, the stress applied was $1 \mathrm{MPa}$. The strain was monitored on the faces of each sample using a $50 \mathrm{~mm}$ Demec gauge. Figure 3 shows the creep testing results.

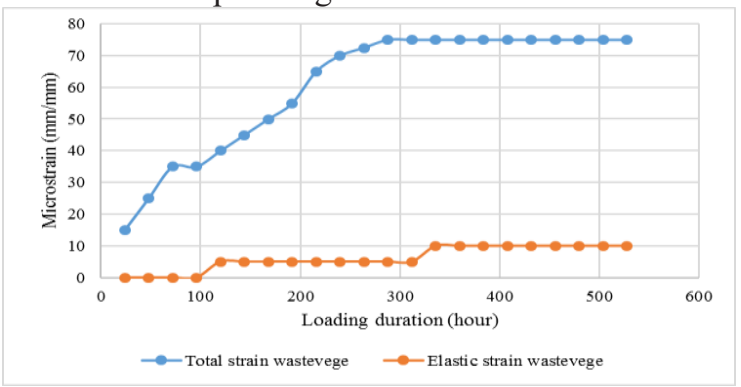

Fig. 3. Possess Specific Creep of wastevege block

\section{7) Oxy-polymerization reaction of waste cooking oil as binder}

Cooking oil is naturally occurring triacylglycerol (TAG) oil. Oils from different sources contain different functional groups. The functional group influences its properties during a chemical reaction. There are various functional groups of TAG oils, which includes; carbon-carbon double bonds, epoxy, and hydroxyl groups. The waste cooking oil used in this study contained carbon-carbon double bonds as functional group and the major constituents are Myristic saturated, Palmitic saturated, Stearic saturated, oleic monounsaturated, and linoleic polyunsaturated.

The characterization of the oil had shown $45 \%$ of linoleic polyunsaturated fatty acid (see Table 3). The polyunsaturated fatty acid contained double bonds separated by two single bonds. The linoleic acid played a significant role in the chemical reactivity of the oil during curing, resulting in the autoxidation, then polymerization in the presence of oxygen. The autoxidation process starts with dehydrogenation of unsaturated fatty acids by atmospheric oxygen, during which dehydrogenated radicals are formed. This is followed by chain polymerization for hydro peroxide formation. Cross-linking for the formation of large molecules concludes the reaction.

The oil also contains a significant amount of stearic acid (12\%) which is a good drying component, during the polymerization process the stearic acid help formed a strong film that is highly resistant to water and alkali. The formation of the film begins with induction, through which the stearic acid is autocatalysed, thus increasing the absorbed oxygen. This is followed by the initiation, whereby the formed film continues to absorb more oxygen resulting in increased mass of the film. Rearrangement of stearic acid double bond occurs, leading to the formation of hydroxyl and hydroperoxy. The induction and initiation 
processes decreased the number of double bonds as a result of cross-linking, thus forming larger molecules.

The bonding ability of the oil can be attributed to the chemical reaction of TAG molecules of the oil by the carbon-carbon double bonds of the unsaturated acids, which allows them to react with oxygen resulting into polymerization.

\section{8) Fourier Transform Infrared spectroscopy (FTIR)}

Investigation of the waste cooking oil used as a binder was carried out using Fourier Transform Infrared spectroscopy (FTIR). The FTIR helps collects the "chemical fingerprint" with detailed information on its composition and structure. FTIR was done on virgin oil and thin film layers of cured oil for 4, 6, 8, and 10 days. The expansion of v (OH) and $\mathrm{v}(\mathrm{CH})$ region is between 4000 and $450 \mathrm{~cm}^{-1}$.

FTIR result shows band at 3006 and $2925 \mathrm{~cm}^{-1}$. The $2925 \mathrm{~cm}^{-1}$ band can be attributed to the symmetric stretching vibration of the aliphatic $\mathrm{CH} 2$ group. This is indicating the presence of hydrogen - carbonyl bond coupled by cis - double bond $(=\mathrm{CH})$ in the oil. The band at $1746.60 \mathrm{~cm}^{-1}$ is as a result of stretching vibration of the carbonyl group in the ester linkage in triacylglycerol's. A broadening of this band is an expected oxidation feature as the concentration of carbonyl containing secondary oxidation products such as aldehydes and ketones increases [16] The band at $1637.96 \mathrm{~cm}^{-1}$ in the virgin oil is as a result of $\mathrm{C}=\mathrm{C}$ stretching in cis - double bonds. This band disappears as the curing progresses as well as band at $3006 \mathrm{~cm}^{-1}$. The indication of the band at $\left.1784.36 \mathrm{~cm}^{-1}\right)$ (4 days cured sample) is a strange feature of oxidation of vegetable oil, though it occurs in oil based paints [17], this may be as a result of multiple oxygenated functions in close proximity e.g. organic carbonates, lactones, or acid anhydrides [18,19,20]. The breakdown and cross-linking of hydrocarbon chains is therefore occurring simultaneously during the curing process.

\section{Conclusion}

Cooking oils are a significant renewable source of materials, and based on this study, we concluded that Waste cooking oil can be used as a sustainable binder in the production of building block with good properties that can be compared with the conventional blocks.

The production of WasteVege block does not require the use of any form of cementitious or pozzolanic materials or water. The products can be considered as more environmentally friendly than cementitious and kiln manufactured blocks/bricks, both of which are high energy consumers. Most importantly, successful implementation and adoption of the WasteVege block concept will inadvertently contribute towards reducing Greenhouse gases (GHG) emissions.

The corresponding author is sincerely grateful to Heriot-Watt University, Putrajaya, Malaysia and Universiti Teknologi Petronas for all the financial support in the course of this study.

\section{References}

1. Gerard Lligadas, Juan C. Ronda, Marina Galià, Virginia Cádiz, Renewable polymeric materials from vegetable oils: a perspective, Material Today Volume 16, Issue 9, Pages 337-343 (September 2013)

2. C. Baillie, Green Composites: Polymer Composites and the Environment, Woodhead Publishing, 2004 
3. Negishia H., Nishida M., Endo Y., and Fujimoto K., „Effect of a Modified Deep-Fat Fryer on Chemical and Physical Characteristics of Frying Oile Journal of American Oil Chemists, Jan (163-166) 2003

4. Sundance Renewables: http://www.sundancerenewables.org.uk/biodp/uvo.htm, (Oct. 2005)

5. Booth E., Bell J., and Mcgovern R., SAC Consultancy Division, Hodsman L., National Non- Food Crops Centre, "Review of the Potential for On-Farm Processing of Various Non-Food Crop Products", NNFCC, (May 2007)

6. Kilpatrick J., ADAS UK Ltd, „West Midlands Non-Food Crops Opportunities/ Mapping Study"e, Advantage West Midlands, Oct. (2007)

7. Calais P. and Clark A. R., "Waste Vegetable Oil as a Diesel Replacement Fuel", http://www.shortcircuit.com.au/warfa/paper/paper.htm and http://www.energysavingnow.com, (2000)

8. ASTM C 136-96a BS 1337 Standard Test Method for Sieve Analysis of Fine and Coarse Aggregates

9. ASTM C127-88 \& C128-88 Standard Test Method for Density, Relative Density (Specific Gravity), and Absorption of Fine Aggregate

10. ASTM C39/C 39MM-14a Standard Test Method for Compressive Strength of Cylindrical Concrete Specimens (2009)

11. ASTM C67-03a ASTM C 67- 03a Standard Test Methods for Sampling and Testing Brick and Structural Clay Tile, (2009)

12. ASTM D4843 - 88, Standard Test Method for Wetting and Drying Test of Solid Wastes (2009)

13. ASTM C 512-02 Standard Test Method for Creep of Concrete in Compression

14. Standard Methods for the analysis of oils, fats and derivatives, Method 2.301 and 2.302

15. Srinivasa Reddy V, Rajaratnam V, Seshagiri Rao M V, Sasikala Ch, Mathematical Model for Predicting Stress-Strain Behaviour of Bacterial Concrete, International Journal of Engineering Research and Development, Volume 5, Issue 11 (February 2013), PP. 21-29]

16. T. Heaton, C. Sammon, J. Ault, L. Black, J.P. Forth, Masonry units bound with waste vegetable oil - Chemical analysis and evaluation of engineering properties, Construction and Building Materials 64, 460-472 (2014)

17. Meilunas R.J, Bentsen J.G, Steinberg A. Analysis of aged paint binders by FTIR spectroscopy. Stud Conserv; 35(1):33-51. (1990)

18. Mallegol J, Gonon L, Lemaire J, Gardette JL. Long-term behaviour of oil-based varnishes and paints-Influence of film thickness on the photooxidation. Polym Degrad Stabil; 72(2):191-7 (2001)

19. Smith B. Infrared spectral interpretation: a systematic approach. 1st ed. CRC Press; (1999)

20. Socrates G. Infrared and Raman characteristic group frequencies. Tableees and charts. 3rd ed. Wiley; (2001) 